\title{
Overview of the Indications and Contraindications for Liver Transplantation
}

\author{
Stefan Farkas, Christina Hackl, and Hans Jürgen Schlitt \\ Department of Surgery, University Medical Center Regensburg, D-93053 Regensburg, Germany \\ Correspondence: hans.schlitt@klinik.uni-regensburg.de
}

Liver transplantation is the only definitive treatment option for patients with irrevocable acute or chronic liver failure. In the last four decades, liver transplantation has developed from an experimental approach with a very high mortality to an almost routine procedure with good short- and long-term survival rates. Here, we present an up-to-date overview of the indications and contraindications for liver transplantation. It is shown how the evaluation of a candidate and finally listing for transplantation has to be performed in a multidisciplinary setting. Meticulous listing, timing, and organ allocation are the crucial factors to achieve an optimal outcome for the individual patient on the one hand, and reasonably using the limited deceased donor pool on the other hand. Living-donor liver transplantation is demanding but necessarily increasing. Because patients after liver transplantation need lifelong aftercare, it is important for primary care clinicians to understand the basic medical problems and risks.

$\mathrm{D}_{\mathrm{n}}^{\mathrm{e}}$ espite significant improvements in the medical management of the complications of liver cirrhosis including hepatocellular carcinoma, liver transplantation (LTx) remains the only definitive treatment option for patients with end-stage liver disease. Significantly improved graft and patient survival rates have been observed over time and, in the last 15 years, are relatively stable, with an overall survival rate of $85 \%$ in the first year and $~ 75 \%$ at $5 \mathrm{yr}$ (Kim et al. 2013). However, $\sim 10 \%$ of patients listed for LTx die on the waiting list (Kim et al. 2006), and many potential candidates are not listed because of the shortage of deceased donor organs (Fig. 1). Other patients are not candidates because of comorbidities, psychosocial issues, and medical issues like hepatocellular carcinoma ex- ceeding a designated size. Acute liver failure is less common but has an excellent outcome if the patient is transplanted promptly.

\section{HISTORY}

The pioneer of human orthotopic liver transplantation, Thomas E. Starzl, learned about experimental auxiliary liver transplant models in dogs while attending a lecture by C. Stuart Welch in 1957 (Starzl 2012). After discussing and refining these canine models, Starzl was the first to attempt an orthotopic liver transplant into a 3-yr-old human recipient suffering from biliary atresia in 1963 (Starzl et al. 1963). The patient did not survive the operation. After several equally unsuccessful attempts, Starzl

Editors: Laurence A. Turka and Kathryn J. Wood

Additional Perspectives on Transplantation available at www.perspectivesinmedicine.org

Copyright (C) 2014 Cold Spring Harbor Laboratory Press; all rights reserved; doi: 10.1101/cshperspect.a015602

Cite this article as Cold Spring Harb Perspect Med 2014;4:a015602 
S. Farkas et al.

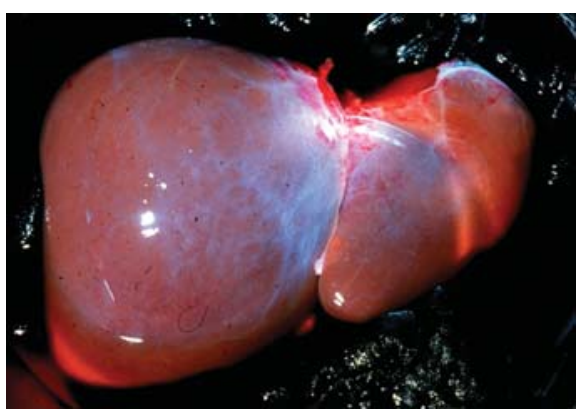

Figure 1. Liver of a deceased organ donor.

succeeded in performing an orthotopic liver transplant into a patient diagnosed with hepatoblastoma in 1967 (Starzl et al. 1968). This patient survived for 18 mo before dying from metastatic disease. During the following years, major breakthroughs such as the expansion of the organ donor pool by introduction of the brain-dead criteria in 1968 (Shapiro 1968), refined surgical technique, and, last but not least, introduction of new immunosuppressive medication such as cyclosporine in 1979 (Starzl et al. 1981a,b) led to a significant increase in liver transplantation. In 1983, the NIH declared that liver transplantation was a valid therapy for end-stage liver disease (National Institutes of Health 1984), and, a few years subsequently, the United Network for Organ Sharing (UNOS) was founded (United States Congress 1984). Already in 1967, the Eurotransplant (ET) International Foundation was founded in Leiden, The Netherlands. In 1988, Rudolf Pichlmayr was the first to perform a split-liver transplantation, offering one liver to two recipients (Pichlmayr et al. 1988). In 1988 and 1989, living-donor liver donation was successfully introduced in the adult-to-pediatric and adult-toadult settings (Fig. 2) (Broelsch et al. 1990). As of today, approximately 6200 and 1700 liver transplants are performed each year within the UNOS and ET networks, respectively.

\section{INDICATIONS FOR LIVER TRANSPLANTATION}

Indications for liver transplantation are manifold and can be classified into end-stage liver disease, acute liver failure, and certain benign and malignant liver tumors. An overview is given in Table 1. Liver transplantation should be considered for any patient in whom anticipated overall survival exceeds life expectancy of the underlying disease or where a significant increase in quality of life can be achieved. Within the UNOS and ET networks, liver cirrhosis caused by chronic viral hepatitis and alcohol abuse is the major cause for end-stage liver disease, accounting for $\sim 70 \%$ of liver transplantations (Zakhari 2013).

Liver transplantation for malignant disease is a medical and ethical challenge with regard to long-term oncological outcome under immunosuppressive therapy and allocation justice because of organ shortage. Childhood hepatoblastoma (Meyers et al. 2012), epitheloid hemangioendothelioma (Grossman and Millis 2010), and limited hepatocellular carcinoma (HCC) (Dhir et al. 2012; Lim et al. 2012), within the Milan criteria (one lesion $\leq 5 \mathrm{~cm}$, or two to three lesions each $\leq 3 \mathrm{~cm}$, no extrahepatic lesion and no vascular invasion), are standard indications for liver transplantation. Patients diagnosed with HCC-often presenting in good clinical condition - therefore receive additional MELD (model of end-stage liver disease) points according to HCC tumor size and waiting time to enable transplantation before the tumor exceeds the Milan criteria (Earl and Chapman 2013). Surgical resection and therapeutic interventions to control HCC progress during the waiting period as well as liver transplantation for patients exceeding the Milan criteria are a

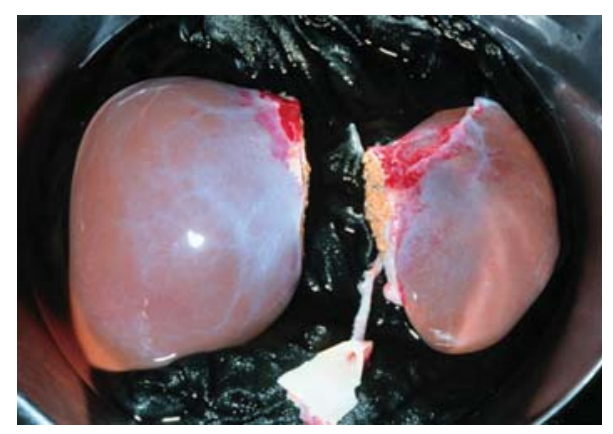

Figure 2. Splitting of liver for two recipients: one adult and one pediatric. 
Table 1. Indications for liver transplantation

\section{Acute liver failure}

Hepatitis A/B

Intoxication (e.g., acetaminophen, death cap)

Wilson's disease

Budd-Chiari syndrome

Chronic liver failure: Noncholestatic cirrhosis Hepatitis B/C

Autoimmune hepatitis

Alcohol-induced cirrhosis

Chronic liver failure: Cholestatic cirrhosis

Primary biliary cirrhosis (PBC)

Primary sclerosing cholangitis (PSC)

Secondary biliary cirrhosis

\author{
Chronic liver failure: Metabolic \\ Wilson's disease \\ Hemochromatosis \\ $\alpha-1$ Antitrypsin deficiency \\ Amyloidosis \\ Cystic fibrosis \\ Tyrosinemia
}

\section{Chronic liver failure: Vascular \\ Budd-Chiari syndrome}

Other indications

Primary oxalosis

Gycogen storage diseases

Hyperlipidemia

Polycystic liver disease

Malignant disease

Hepatocellular carcinoma (HCC, within Milan criteria)

Fibrolamellar carcinoma (FLC)

Hepatoblastoma

Epitheloid hemangioendothelioma

Cholangiocellular adenocarcinoma

Neuroendocrine liver metastases

\section{Benign liver tumors}

Adenomatosis

Liver transplantation in pediatric patients

Biliary atresia

Byler's disease

Alagille's syndrome

Neonatal hepatitis/neonatal viral hepatitis

Autoimmune hepatitis

Hepatoblastoma focus of ongoing clinical research (Yao 2008). Living-donor liver transplantation may here offer a treatment option for selected HCC patients to minimize waiting time or enable liver transplantation in tumors exceeding the Milan criteria (Grant et al. 2013). In contrast, patients diagnosed with intrahepatic cholangiocellular adenocarcinoma (CCA) have shown poor long-term overall survival after liver transplantation and are not transplant candidates (Ali et al. 2011). However, recent clinical trials by the Mayo Clinic evaluating a multimodality treatment concept for CCA combining neoadjuvant radiochemotherapy and liver transplantation have established CCA as an indication for liver transplantation in selected patients with unresectable hilar CCA or CCA arising in patients with primary sclerosing cholangitis (Rosen et al. 2010; Darwish Murad et al. 2012). Clinical trials evaluating liver transplantation for selected patients with neuroendocrine hepatic metastases have shown long-term graft and patient survival comparable with patients transplanted for HCC (Gedaly et al. 2011). In individual cases, patients with neuroendocrine liver metastases thus are eligible for liver transplantation. Extrahepatic malignancies as well as hepatic metastases from non-neuroendocrine tumors so far remain absolute contraindications for liver transplantation. However, a recent Norwegian pilot study evaluating liver transplantation for unresectable colorectal liver metastases showed that overall survival exceeds by far the reported outcome for chemotherapy, is comparable with overall survival after liver resection for resectable colorectal liver metastases, and is comparable with overall survival after repeat liver transplantation for nonmalignant diseases (Hagness et al. 2013). Thus, ongoing improvements in multimodality cancer therapy may in the future widen indications for liver transplantation in malignant disease.

\section{CONTRAINDICATIONS FOR LIVER TRANSPLANTATION}

Absolute and relative contraindications for liver transplantation are shown in Table 2. Abstinence from alcohol and drug abuse for a minimum of 
S. Farkas et al.

Table 2. Contraindications for liver transplantation

\begin{tabular}{lc}
\hline $\begin{array}{l}\text { Absolute } \\
\text { contraindication }\end{array}$ & $\begin{array}{c}\text { Relative } \\
\text { contraindications }\end{array}$ \\
\hline Active alcohol abuse & Psychosocial conditions \\
Uncontrolled systemic & Advanced age \\
infections & Severe hepatopulmonary \\
Uncontrolled & or severe hepatorenal \\
extrahepatic & syndrome \\
malignancy & Severe obesity/ \\
Uncontrolled/limiting & malnutrition \\
medical conditions & m
\end{tabular}

$6 \mathrm{mo}$ is required in the UNOS, ET, and other transplant programs. This mandatory duration of abstinence is a matter of debate because the 6mo threshold has shown to be insufficient for predicting long-term graft and patient survival (Rice and Lucey 2013). Although uncontrolled systemic infections, which exclude patient survival under immunosuppression, and AIDS-defining symptoms in HIV patients are absolute contraindications, the possibility of performing a liver transplantation in patients diagnosed with infections such as HBV and HIV and controllable local infections must be assessed for each individual patient (Grossi 2003; Tavio et al. 2011; Campsen et al. 2013). Further absolute contraindications for liver transplantation are life-limiting medical conditions such as advanced cadiovascular, pulmonary, or neurologic disorders; intrahepatic CCA; hepatic metastases other than neuroendocrine metastases in selected patients; and extrahepatic malignancy (see also Lakkis and Lechler 2013).

Patients diagnosed with HCC exceeding the Milan criteria can still be candidates for liver transplantation, depending on local or national allocation guidelines (Yao 2008; Grant et al. 2013). In cancer survivors with complete remission, a tumor-free survival of $2-5 \mathrm{yr}$, depending on the type of malignancy, is required before listing for liver transplantation (Bachir and Larson 2012).

Relative contraindications may be psychosocial conditions resulting in poor compliance, advanced age, and severe hepatopulmonary or hepatorenal syndrome that may not be cured or improved after liver transplantation, as well as severe obesity or severe malnutrition. Here, the indication must be assessed individually for each patient.

\section{EVALUATION}

From a transplant-physician viewpoint, patients should be referred for consideration for liver transplantation as early as possible. Referral does not automatically mean listing of the patient, but allows thorough assessment of candidacy for transplant before listing. If the interdisciplinary decision is made that the patient is eventually a candidate for listing, an extensive patient evaluation is performed (Table 3).

After exclusion of absolute contraindications and discussion of relative contraindications, several medical, psychosocial, and ethical questions have to be answered:

- Can the patient survive the operation and postoperative period?

- What gain of lifetime and what quality of life will the patient have after transplantation?

- Will the patient be compliant regarding the medical regimen?

- In patients with alcoholic liver disease and/ or a history of drug abuse, besides being abstinent for at least $6 \mathrm{mo}$, what is the chance of the patient staying abstinent lifelong?

- Psychosocial issues: Do psychological disorders or lack of social support compromise long-term outcome?

- Is living donation an option?

Some comorbidities are discovered only at the evaluation process but can also be corrected before transplantation. As the transplant patient age has increased throughout the years, cardiovascular disease is common and has to be treated before listing. An increasing number of patients in Western countries suffer from morbid obesity and have to be critically evaluated concerning perioperative risk and probable need of weight loss with or without bariatric surgery. Up to one-third of patients with cirrhosis develop diabetes. These patients require good metabolic control before listing because the re- 
Table 3. Evaluation for liver transplantation

General assessments
Previous medical/surgical history
Physical examination
Vaccinations: Hepatitis A/B, tetanus, diphtheria,
polio
Psychosocial assessment by psychiatrist
Assessment by hepatologist
Consult with transplant surgeon
Blood tests
ABO and Rhesus blood group, full blood count,
electrolytes, BUN, creatinine, creatinine-clearance,
coagulation (INR, APTT, factor II, factor V), liver
function tests, glucose, ferritine, transferrine,
protein electrophoresis, thyroid hormones, tumor
marker (AFP, CA19-9, CEA, CA125 in females;
PSA in males), isotypes of antibodies (IgA, IgG,
IgM, ANA, AMA)
Urinalysis and microscopy

\section{Microbiology/virology}

Hepatitis serology (Hepatitis A/B/C/D), CMV IgG/ IgM, EBV IgG/IgM, VZV IgG/IgM, HIV, tuberculosis

\section{Screening for infections/tumors \\ Maxillofascial/dental examination \\ ENT examination \\ Dermatological examination \\ Gynecology/urology examination \\ Gastroscopy \\ Coloscopy in patients at risk or $>40 \mathrm{yr}$}

\section{Preparation for surgery}

Pulmonary function test and blood gas analysis

EKG and echocardiography

Cardiac catheterization in patients at risk or $>65 \mathrm{yr}$

Assessment by transplant anesthetist

\section{Radiologic assessment}

$\mathrm{X}$ ray of paranasal sinuses

Thoracic and abdominal three-phase angio-CT scan Mammography in female patients at risk or $>40 \mathrm{yr}$ Duplex-sonography of the liver

\section{Final assessment}

Interdisciplinary review by transplant board (hepatologist, transplant surgeon, transplant anesthetist, psychiatrist) quired immunosuppression itself increases the risk of and probably worsens preexisting diabetes mellitus (Prokai et al. 2012).

Portopulmonary hypertension and hepatopulmonary syndrome may be reversed by liver transplantation. However, uncontrolled portopulmonary hypertension during the transplantation procedure may cause severe anesthesia problems and severe damage to the graft due to elevated central venous pressure.

Hepatorenal syndrome may also be reversed after transplantation, but a simultaneous listing for liver and kidney may be considered if persistence of chronic kidney disease is suspected (Angeli and Gines 2012). Because the results of a simultaneous liver and kidney transplantation are critical (Papafragkakis et al. 2010), with an increased loss of kidneys in the Eurotransplant area, the following solution was found. Patients listed simultaneously for liver and kidney can be first transplanted with a liver alone and receive extra points on the kidney waiting list. If they are still in need of a kidney transplant (clearance is $<15 \mathrm{~mL} / \mathrm{min}$ ) $90-360 \mathrm{~d}$ after liver transplantation, they have the chance to receive a kidney transplant within 3 mo. Thus, loss of kidneys during simultaneous transplantation, early death with a functioning kidney graft, and unnecessary kidney transplantations should be prevented. This approach has to be evaluated during the next years.

The listing criteria by the UNOS state that LTx candidates can be listed for kidney transplantation too if they have a documented stage 4-5 chronic kidney disease, acute kidney injury with a glomerular filtration rate lower than $25 \mathrm{~mL} / \mathrm{min}$ continuously for $6 \mathrm{wk}$, or a metabolic disease such as hyperoxaluria.

Patients with HCC who are eligible for an exceptional MELD (eMELD) have to be evaluated concerning the specificity of the lesion and the size and number of tumors and vascular infiltration in the liver. Furthermore, extrahepatic spread has to be excluded. For that purpose, imaging with MRI and CT and-for specificity of the typical arterial hyperperfusion in the HCC lesion-contrast enhanced ultrasound (CEUS) is recommended. Thus, it can be evaluated if the patient fits, for example, in the Mi- 
S. Farkas et al.

lan criteria or the UNOS criteria for listing with exceptional MELD. These patients should be also evaluated concerning bridging strategies until the expected time of transplantation. Here interventional radiologists and oncological liver surgeons should be included.

\section{LISTING AND TIMING AND ALLOCATION OF LTX}

Listing

After extensive evaluation, the final listing of the patient is an interdisciplinary process. In the liver transplantation board, transplant surgeons, transplant hepatologists, anesthesiologists, radiologists, transplant coordinators, and psychiatrists should be included. All participate in the decision of listing the patient formally for transplantation (Dawwas and Gimson 2009).

\section{Timing and Allocation}

Timing is crucial for the success of liver transplantation. On the one hand, best results are achieved if the patient is not decompensated and still in a good general condition. On the other hand, the decompensated and sickest patients are the ones who most urgently need transplantation-but have the worst outcome. Owing to organ shortage, different allocation solutions are in use but are currently intensively discussed. A model for the sickest-first policy, MELD, was implemented in the allocation in the UNOS area in 2002 and in the Eurotransplant area in 2007. It consists of serum creatinine, international normalized ratio (INR), and bilirubin (patientbased allocation). The MELD calculator can be found, for example, on the following website (www.mayoclinic.org/meld/mayomodel6.htm). The MELD was originally developed to predict 3-mo survival after transjugular intrahepatic portosystemic shunt replacement (Malinchoc et al. 2000; Said et al. 2004). Since implementation of the MELD system, waiting list mortality has declined. However, patients with very high laboratory MELD scores $(>35)$ are normally ICU-bound, on dialysis, and often require vasopressor support and artificial ventilation. If these patients are transplanted and not temporarily delisted until recovery, the 1-yr mortality is very high. Studies are ongoing to assess whether the addition of parameters that are associated with poor patient outcome (serum sodium, renal failure, and serum albumin) will improve the predictive ability of MELD (Biggins et al. 2005; Kim et al. 2008).

"Center-based allocation" is in use especially in countries with few transplant programs, for example, in Australia, the United Kingdom, and Austria. Moreover, it is used parallel to the MELD system for extended criteria donors and for recipients who are stable but not well represented in the MELD system. The advantage of center-based allocation is that the physicians can match the organ to the patient, which results in a relatively good outcome although extended criteria organs are used.

"High-urgency allocation" is generally only possible in case of acute liver failure (see above) or for retransplantation.

\section{DECEASED-DONOR LIVER TRANSPLANTATION (DDLT)}

The deceased-donor pool is limited. Thus, in the last decade, different strategies have been implemented to increase the pool of deceased liver donation and transplantation. Donation after brain death is widely accepted and well established. Donation after cardiac death (DCD) is well established, for example, in the UNOS area, but still controversial in Europe. The results after DCD transplantation are not as good compared with donation after brain death; however, it seems to be a feasible source to increase the donor pool. In addition, older donors are increasingly accepted, because in some countries the majority of donors are $>50 \mathrm{yr}$. Absolute contraindications for deceased organ donation are cancer and uncontrolled infections (e.g., hepatitis). Cardiac arrest, hypotension, high sodium, and liver steatosis are not absolute contraindications. Macroscopic evaluation of the liver at time of retrieval (before and after perfusion with cold storage solution) is very important to assess organ quality. Frozen sections may not always be available at the donation site and are 
not optimal to evaluate the degree of steatosis. Extension of the donor pool by use of marginal grafts may result in higher complication rates such as early graft failure, biliary complications (ischemic type biliary lesions), and need for retransplantation (Busuttil and Tanaka 2003).

Another technique to increase the donor pool is split-liver transplantation. Optimal grafts can be split into an extended right lobe for an adult recipient and a left lateral lobe for a pediatric recipient (Fig. 3). Also, so-called full splits (right and full left lobe for two adult recipients) are used in some cases (Gundlach et al. 2000). These techniques-if used in experienced centers-do have good long-term results but are often limited by logistic and thus ischemic time problems if the split is allocated to two different centers.

\section{LIVING-DONOR LIVER TRANSPLANTATION (LDLT)}

Living-donor liver transplantation (LDLT) is an established method with increasing numbers worldwide. In Asian countries, close to $90 \%$ of liver transplantations are from living donors because of social and religious factors. In western countries and especially in the UNOS area, some recent donor deaths led to a decline in LDLT numbers. The advantage of LDLT is the use of an optimal healthy donor, minimal ischemic time, elective surgery, and timing of transplantation owing to the recipient's need and medical stability and not to deceased organ availability. A further advantage of LDLT is the possibility of ABO-incompatible transplantation (Song et al. 2013). However, living donation is not without risk for the healthy donor, and LDLT is surgically more demanding than whole-organ transplantation. The remaining liver in the donor regenerates within 3 mo to $90 \%$ of its original volume. The donor has a risk of a $30 \%$ morbidity and a mortality risk of up to $0.8 \%$ (Ghobrial et al. 2008). Especially, the bile duct system has to be evaluated intraoperatively by cholangiogram, and aberrant bile ducts have to be taken care of meticulously (Jeon et al. 2013). In addition, the venous outflow in the recipient is crucial, and

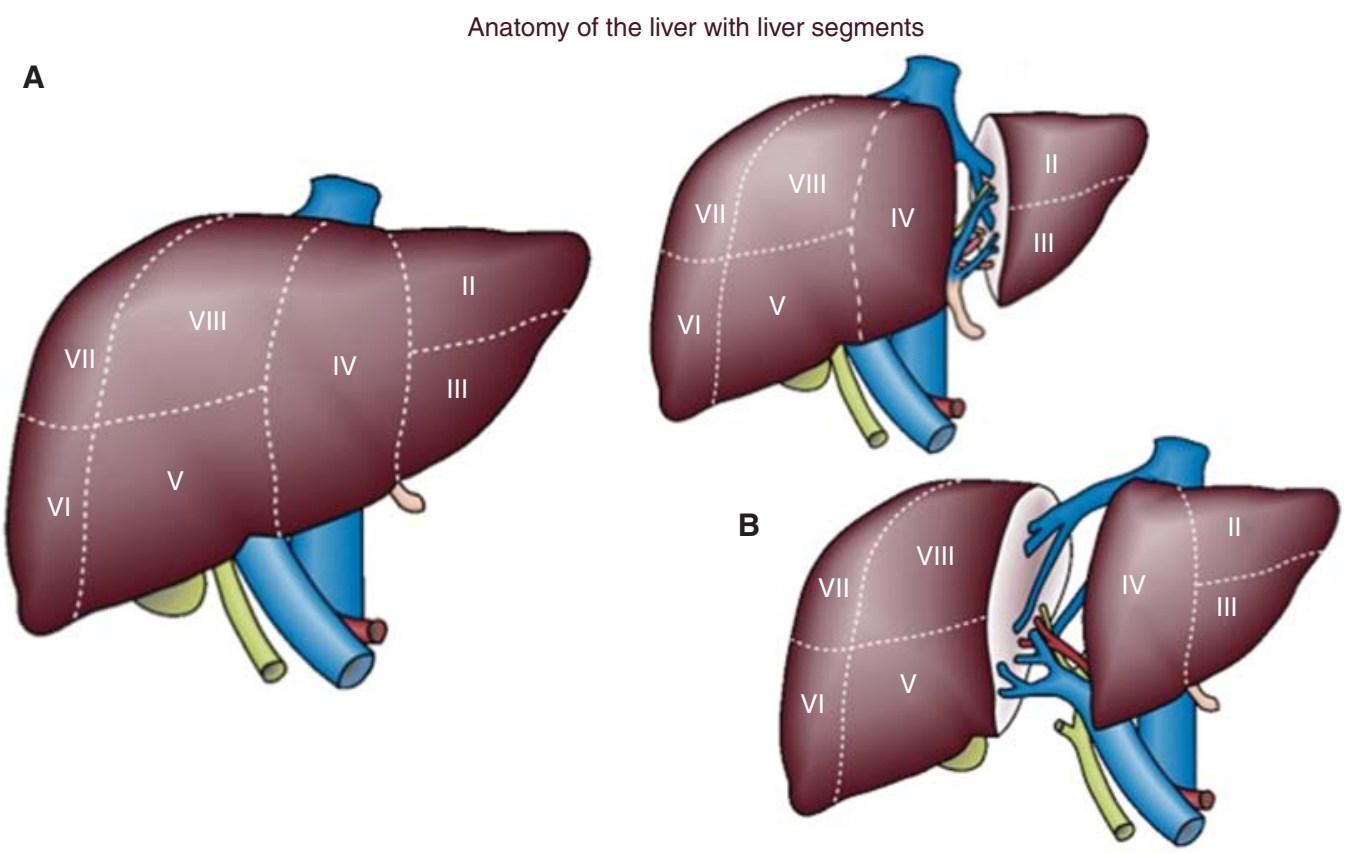

Figure 3. Anatomy of the liver with liver segments (seg). (A) Left lateral splitting or living donation of seg II/III for a pediatric recipient. (B) Living donation of the right lobe (seg V, VI, VII, VIII) for an adult recipient. 
S. Farkas et al.

Table 4. Supplemental evaluation of the donor for living donor liver transplantation

Blood tests
Fibrinogen, AT III, protein C, protein S, factors VII
and VIII, CRP, triglycerides, cholesterol, LDL, HDL
Virology
Anti-HAV, HbsAg, anti-HBc, HBV-DNA, anti-HBe,
anti-HBs, anti-HCV, HCV-RNA
Other
MRSA-screening, stress-EKG, CT-volumetry of liver
segments to be donated, and remaining liver
Liver biopsy in patients with elevated GGT or
BMI > 30
Final discussion in ethics board confirming informed
consent and voluntariness of liver donation.

branches of the middle vein may have to be reconstructed. Moreover, in adult LDLT, smallfor-size syndrome is sometimes a problem. Thus, a precise imaging evaluation with threephase CT angiography and volume measurement of the future liver remnant of the donor as well as of the graft size have to be performed and calculated with the patient body weight. For all LDLT, careful selection and extensive evaluation of the donor are very important (Table 4) (Berg et al. 2007). All ethical, legal, and insurance aspects have to be cleared with the authorities and well documented. Altogether, a risk adjustment for the donor and the recipient has to be performed multidisciplinarily. The risk of the recipient must equal or exceed the risk of the donor (Thuluvath and Yoo 2004).

\section{LIVER TRANSPLANTATION-TECHNIQUES}

The transplant operation itself has been significantly standardized and optimized during the last two decades. Nowadays liver transplantation in a stable donor with a standard donor organ is a routine operation and may be performed without any blood transfusion and only few plasma replacements. However, the standards developed for liver transplantation after deceased donation are different based on surgical training.
First, the native liver has to be explanted via right angular incision. Here, two different methods are used: replacement of the inferior vena cava (IVC) or so-called piggyback, in which the inferior vena cava is preserved. The clamping of the IVC needed for resection can decrease blood pressure and can cause cardiac problems difficult to manage for the anesthetist. Moreover, renal insufficiency may be a problem because of clamping of the IVC causing reduced perfusion of the kidneys. Recently, in a Cochrane database analysis, the piggyback technique versus standard technique was reviewed, and they found two randomized trials with a total of 106 patients (Gurusamy et al. 2011b). Warm ischemic time was shorter in the piggyback method because only one caval anastomosis had to be performed. However, the proportion of patients who developed chest complications was significantly higher with the piggyback method. There was no significant difference in postoperative death, primary graft nonfunction, complications related to the blood vessels, kidney failure, blood transfusion requirements, or ICU stay or hospital stay between the two groups. In our institution, we prefer replacement of the IVC because we see a substantial shortening of operation time.

To reduce the effects of clamping, the IVC and also the portal vein - which may cause mesenterial congestion-veno-venous bypass was once widely used and has now developed a revival in some centers. There are different techniques described for the bypass: open or percutaneous, heparin-coated or no heparin-coated. This was reviewed as well in a Cochrane database analysis, and no difference regarding renal failure or blood transfusions was found between the groups in two randomized trials (Gurusamy et al. 2011a). The operating time was significantly shorter in the percutaneous bypass group. To aim at a short operating time, we perform no veno-venous bypass at all at our center.

Another point of discussion is the technique of flushing and reperfusion for liver transplantation. Marginal organs are prone to ischemic time biliary lesions (ITBL) due to reduced flow in the pericanalicular arteries of the bile ducts. Here some studies hint that the way and se- 
quence of reperfusion influence the rate of ITBL (Heidenhain et al. 2006; Farid et al. 2011). The Cochrane database analysis searched for comparisons that included initial hepatic artery flush versus initial portal vein flush or simultaneous flushing and different types of blood venting or use of perfusion fluid (Gurusamy et al. 2012). There was no significant difference in mortality, graft survival, or severe morbidity rates in any of the comparisons.

Bile duct reconstruction can be performed with a duct-to-duct or duct-to-small-bowel anastomosis. Duct-to-small-bowel is recommended for patients with PSC. Placing a Ttube or not in the bile duct remains controversial (Gastaca et al. 2013). The bile duct system and the common bile duct remain the Achilles heel of transplantation, because they are most sensitive to early ischemic injury already during cold storage. We developed a histological bile duct risk score that predicts biliary complications and may help decision making in LTx (Brunner et al. 2013).

\section{POSTTRANSPLANT CARE}

Lifelong aftercare is crucial for long-term graft and patient survival after liver transplantation. During the early postoperative phase, daily blood tests are necessary for surveillance of liver function, coagulation, electrolytes, and target blood levels of immunosuppressive drugs. Factor VII, being produced by the liver and having a half-life of $6 \mathrm{~h}$, is an excellent parameter to assess liver function on a daily basis. Prophylactic antibiotic therapy is given for $3 \mathrm{~d}$ perioperatively. Prophylactic treatment for CMV and PCP infections should be given according to the donor/recipient risk profile (Lautenschlager 2009). Regular duplex-sonography is performed to assess liver perfusion.

Daily immunosuppressive therapy is mandatory to prevent organ rejection. Especially in the early posttransplant phase, immunosuppressive therapy consists of complex combinations of various drugs and needs to be adapted for each patient individually. Components are antilymphocyte antibodies, steroids, calcineurin inhibitors, and inhibitors of $\mathrm{B}$ - and $\mathrm{T}$ - cell proliferation (Scherer et al. 2007). Standard immunosuppressive combination regimens are basiliximab, MMF, cyclosporine, and prednisolone or basiliximab, MMF, sirolimus/everolimus, and prednisolone (Farkas et al. 2009). The chimeric monoclonal T-cell IL-2-receptor antibody basiliximab is given on $\mathrm{d} 0$ and 4 after liver transplant for induction therapy. Mycophenolate mofetil (MMF), a reversible inhibitor of inosine monophosphate dehydrogenase in purine synthesis, reduces proliferation of $B$ and $\mathrm{T}$ cells (Schlitt et al. 2013). Calcineurin inhibitors such as cyclosporine inhibit T-cell production and excretion of IL-2. mTor inhibitors such as sirolimus and everolimus also inhibit the proliferation of B and T cells. However, in contrast to calcineurin inhibitors, mTor inhibitors show no renal toxicity (Schnitzbauer et al. 2010). The main side effects are bone marrow toxicity, inhibition of wound healing, and reduction of liver function. On the other hand, mTor inhibitors lower cancer risk in selected patients and therefore are recommended especially for patients transplanted for malignant disease (Law 2005). Steroids inhibit T-cell activation and block IL-1 and IL-2 synthesis. Steroids are the backbone of all immunosuppressive regimens and are given already before reperfusion of the transplanted organ intraoperatively. In the early postoperative phase, steroids are given in high doses but should be gradually reduced. In many patients, steroids can be tapered 6 mo after transplantation (Shapiro 2004), and long-term immunosuppressive therapy often can consist of monotherapy. Because immunosuppressive drugs can interact with many other medications and dietary components, target levels must be checked lifelong on a regular basis, and interactions must be considered when new medications must be introduced.

Although patients must be closely monitored by their transplant center in the early postoperative phase, long-term lifelong aftercare can also, at least in part, be conducted by general practitioners and primary care hospitals. The main focuses of aftercare must be screening for complications and side effects of immunosuppressive therapy, recognition and treatment of acute or chronic graft rejection, recognition 
S. Farkas et al.

and treatment of biliary complications, malignant disease, and recurrence of the primary liver disease. Details are shown in Table 2. Especially, prevention, recognition, and treatment of infections including opportunistic infections are crucial for long-term patient survival because patients under immunosuppressive therapy often do not show typical clinical symptoms or leukocytosis. Infections can worsen rapidly to septic conditions, and infections present the leading cause of mortality after liver transplantation (Fishman and Rubin 1998; Torbenson et al. 1998).

For prevention of malignant disease, patients must be advised to use high sun-protection-factor sunscreen and to quit cigarette smoking. Furthermore, preventive screening examinations should be performed on a frequent basis (see Table 5) (Watt et al. 2009; Chak and Saab 2010). In patients transplanted for hepati-

Table 5. Overview of posttransplant aftercare

\section{General assessments}

Physical examination

Dental examination

Vaccinations: influenza, pneumonia, hepatitis A/B; live virus vaccinations should be avoided.

\section{Screening for nonmalignant disease and} immunosuppressant side effects

Hypertension

Renal dysfunction

Diabetes

Cardiovascular disease

Infection/opportunistic infection

Screening for malignant disease

Annual skin cancer screening

Annual gynecology and mammography screening in women

Annual urologic and PSA screening in men

Colonoscopy at regular intervals (depending on risk factor)

Annual abdominal and pelvic ultrasound

In some centers: Annual chest + abdominal $\mathrm{CT} / \mathrm{MRI}$

Screening for recurrence of primary liver disease Hepatitis B/C, PBC, PSC, autoimmune hepatitis, hemochromatosis, malignancy tis $\mathrm{B} / \mathrm{C}, \mathrm{PBC}$, PSC, autoimmune hepatitis, and hemochromatosis, screening for disease recurrence must be performed. Administration of hepatitis B immune globulin during transplant surgery and at regular intervals, in combination with antiviral therapy, can prevent HBC recurrence (Cholongitas et al. 2011). In contrast, treatment with pegylated interferone monotherapy or combined with ribavirin, owing to liver toxicity, is not started until HCV recurrence is proven (Gurusamy et al. 2010). Patients transplanted for alcoholic liver disease must stay sober after liver transplantation, and also patients transplanted for other indications should cease alcohol consumption.

\section{FUTURE PERSPECTIVES OF LIVER TRANSPLANTATION}

The scarcity of deceased donor organs will remain one of the main problems for patients on the waiting list for liver transplantation. In addition, patients with end-stage liver disease are affected who cannot enter the waiting list at all because of strict allocation rules made to counterbalance the lack of organs. Extension of the deceased donor pool is essential but will reach a limit. Living-donation liver transplantation, which is standard procedure in Asian countries, will have to increase also in Western countries to cover the need for lifesaving organs.

Future immunosuppressive strategies in liver transplantation have to imply three main goals:

- Reduction of side effects like renal insufficiency,

- reduction of cancer recurrence of hepatocellular carcinoma and de novo cancer after transplantation, and

- finally, and optimally, induction of tolerance.

For that purpose, mTOR inhibitors are very interesting because they block the central pathway for vital aspects of tumor development, including angiogenesis and cell growth. mTOR inhibitors have anticancer activities, which may prove critical in the fight against high cancer recurrence and de novo cancer. They furthermore provide the capacity to interfere 
with fibrotic processes that often accompany transplant rejection and to influence the preferential development of immunological tolerance. Studies are ongoing that try to induce tolerance by either stem cell therapy (Dahlke et al. 2009; Dillmann et al. 2012) or by transfusion of regulating cells in the setting of living donation (www.onestudy.org).

\section{REFERENCES}

${ }^{*}$ Reference is also in this collection.

Ali JM, Bonomo L, Brais R, Griffiths WJ, Lomas DJ, Huguet EL, Praseedom RK, Jamieson NV, Jah A. 2011. Outcomes and diagnostic challenges posed by incidental cholangiocarcinoma after liver transplantation. Transplantation 91: $1392-1397$.

Angeli P, Gines P. 2012. Hepatorenal syndrome, MELD score and liver transplantation: An evolving issue with relevant implications for clinical practice. J Hepatol 57: 11351140.

Bachir NM, Larson AM. 2012. Adult liver transplantation in the United States. Am J Med Sci 343: 462-469.

Berg CL, Gillespie BW, Merion RM, Brown RS Jr, Abecassis MM, Trotter JF, Fisher RA, Freise CE, Ghobrial RM, Shaked A, et al. 2007. Improvement in survival associated with adult-to-adult living donor liver transplantation. Gastroenterology 133: 1806-1813.

Biggins SW, Rodriguez HJ, Bacchetti P, Bass NM, Roberts JP, Terrault NA. 2005. Serum sodium predicts mortality in patients listed for liver transplantation. Hepatology 41: 32-39.

Broelsch CE, Emond JC, Whitington PF, Thistlethwaite JR, Baker AL, Lichtor JL. 1990. Application of reduced-size liver transplants as split grafts, auxiliary orthotopic grafts, and living related segmental transplants. Ann Surg 212: 368-375.

Brunner SM, Junger H, Ruemmele P, Schnitzbauer AA, Doenecke A, Kirchner GI, Farkas SA, Loss M, Scherer MN, Schlitt HJ, et al. 2013. Bile duct damage after cold storage of deceased donor livers predicts biliary complications after liver transplantation. J Hepatol 58: $1133-$ 1139.

Busuttil RW, Tanaka K. 2003. The utility of marginal donors in liver transplantation. Liver Transpl 9: 651-663.

Campsen J, Zimmerman M, Trotter J, Hong J, Freise C, Brown R, Cameron A, Ghobrial M, Kam I, Busuttil R, et al. 2013. Liver transplantation for hepatitis B liver disease and concomitant hepatocellular carcinoma in the United States with hepatitis B immunoglobulin and nucleoside/nucleotide analogues. Liver Transpl doi: 10.1002/1t.23703.

Chak E, Saab S. 2010. Risk factors and incidence of de novo malignancy in liver transplant recipients: A systematic review. Liver Int 30: 1247-1258.

Cholongitas E, Goulis J, Akriviadis E, Papatheodoridis GV. 2011. Hepatitis B immunoglobulin and/or nucleos(t)ide analogues for prophylaxis against hepatitis $\mathrm{B}$ virus recur- rence after liver transplantation: A systematic review. Liver Transpl 17: 1176-1190.

Dahlke MH, Hoogduijn M, Eggenhofer E, Popp FC, Renner P, Slowik P, Rosenauer A, Piso P, Geissler EK, Lange C, et al. 2009. Toward MSC in solid organ transplantation: 2008 position paper of the MISOT study group. Transplantation 88: 614-619.

Darwish Murad S, Kim WR, Therneau T, Gores GJ, Rosen CB, Martenson JA, Alberts SR, Heimbach JK. 2012. Predictors of pretransplant dropout and posttransplant recurrence in patients with perihilar cholangiocarcinoma. Hepatology 56: 972-981.

Dawwas MF, Gimson AE. 2009. Candidate selection and organ allocation in liver transplantation. Semin Liver Dis 29: $40-52$.

Dhir M, Lyden ER, Smith LM, Are C. 2012. Comparison of outcomes of transplantation and resection in patients with early hepatocellular carcinoma: A meta-analysis. HPB (Oxford) 14: 635-645.

Dillmann J, Popp FC, Fillenberg B, Zeman F, Eggenhofer E, Farkas S, Scherer MN, Koller M, Geissler EK, Deans R, et al. 2012. Treatment-emergent adverse events after infusion of adherent stem cells: The MiSOT-I score for solid organ transplantation. Trials 13: 211.

Earl TM, Chapman WC. 2013. Transplantation for hepatocellular carcinoma: The North American experience. Recent Results Cancer Res 190: 145-164.

Farid WR, de Jonge J, Slieker JC, Zondervan PE, Thomeer MG, Metselaar HJ, de Bruin RW, Kazemier G. 2011. The importance of portal venous blood flow in ischemic-type biliary lesions after liver transplantation. Am J Transplant 11: $857-862$.

Farkas SA, Schnitzbauer AA, Kirchner G, Obed A, Banas B, Schlitt HJ. 2009. Calcineurin inhibitor minimization protocols in liver transplantation. Transpl Int 22: 49-60.

Fishman JA, Rubin RH. 1998. Infection in organ-transplant recipients. N Engl J Med 338: 1741-1751.

Gastaca M, Andres V, Ruiz P, Ventoso A, de Urbina JO. 2013. T-tube or no T-tube in cadaveric orthotopic liver transplantation: The type of tube really matters. Ann Surg doi: 10.1097/SLA.0b013e31829d56c0.

Gedaly R, Daily MF, Davenport D, McHugh PP, Koch A, Angulo P, Hundley JC. 2011. Liver transplantation for the treatment of liver metastases from neuroendocrine tumors: An analysis of the UNOS database. Arch Surg 146: $953-958$.

Ghobrial RM, Freise CE, Trotter JF, Tong L, Ojo AO, Fair JH, Fisher RA, Emond JC, Koffron AJ, Pruett TL, et al. 2008. Donor morbidity after living donation for liver transplantation. Gastroenterology 135: 468-476.

Grant RC, Sandhu L, Dixon PR, Greig PD, Grant DR, McGilvray ID. 2013. Living vs. deceased donor liver transplantation for hepatocellular carcinoma: A systematic review and meta-analysis. Clin Transplant 27: 140147.

Grossi P. 2003. Liver transplantation in HIV-positive individuals: A new paradigm. Transplant Proc 35: 1005-1006.

Grossman EJ, Millis JM. 2010. Liver transplantation for non-hepatocellular carcinoma malignancy: Indications, limitations, and analysis of the current literature. Liver Transpl 16: 930-942. 
S. Farkas et al.

Gundlach M, Broering D, Topp S, Sterneck M, Rogiers X 2000. Split-cava technique: Liver splitting for two adult recipients. Liver Transpl 6: 703-706.

Gurusamy KS, Tsochatzis E, Xirouchakis E, Burroughs AK, Davidson BR. 2010. Antiviral therapy for recurrent liver graft infection with hepatitis $\mathrm{C}$ virus. Cochrane Database Syst Rev CD006803.

Gurusamy KS, Koti R, Pamecha V, Davidson BR. 2011a Veno-venous bypass versus none for liver transplantation. Cochrane Database Syst Rev CD007712.

Gurusamy KS, Pamecha V, Davidson BR. 2011b. Piggy-back graft for liver transplantation. Cochrane Database Syst Rev CD008258

Gurusamy KS, Naik P, Abu-Amara M, Fuller B, Davidson BR. 2012. Techniques of flushing and reperfusion for liver transplantation. Cochrane Database Syst Rev 3: CD007512.

Hagness M, Foss A, Line PD, Scholz T, Jorgensen PF, Fosby B, Boberg KM, Mathisen O, Gladhaug IP, Egge TS, et al. 2013. Liver transplantation for nonresectable liver metastases from colorectal cancer. Ann Surg 257: 800-806.

Heidenhain C, Heise M, Jonas S, Ben-Asseur M, Puhl G, Mittler J, Thelen A, Schmidt S, Langrehr J, Neuhaus P. 2006. Retrograde reperfusion via vena cava lowers the risk of initial nonfunction but increases the risk of ischemictype biliary lesions in liver transplantation-A randomized clinical trial. Transpl Int 19: 738-748.

Jeon YM, Lee KW, Yi NJ, Lee JM, Hong G, Choi Y, Park MS, Kim H, Suh KS. 2013. The right posterior bile duct anatomy of the donor is important in biliary complications of the recipients after living-donor liver transplantation. Ann Surg 257: 702-707.

Kim WR, Therneau TM, Benson JT, Kremers WK, Rosen CB, Gores GJ, Dickson ER. 2006. Deaths on the liver transplant waiting list: An analysis of competing risks. Hepatology 43: 345-351.

Kim WR, Biggins SW, Kremers WK, Wiesner RH, Kamath PS, Benson JT, Edwards E, Therneau TM. 2008. Hyponatremia and mortality among patients on the liver-transplant waiting list. N Engl J Med 359: 1018-1026.

Kim WR, Stock PG, Smith JM, Heimbach JK, Skeans MA, Edwards EB, Harper AM, Snyder JJ, Israni AK, Kasiske BL. 2013. OPTN/SRTR 2011 Annual Data Report: Liver. Am J Transplant 13: 73-102.

* Lakkis FG, Lechler RI. 2013. Origin and biology of the allogeneic response. Cold Spring Harb Perspect Med 3: a014993.

Lautenschlager I. 2009. CMV infection, diagnosis and antiviral strategies after liver transplantation. Transpl Int 22: 1031-1040.

Law BK. 2005. Rapamycin: An anti-cancer immunosuppressant? Crit Rev Oncol Hematol 56: 47-60.

Lim KC, Chow PK, Allen JC, Siddiqui FJ, Chan ES, Tan SB. 2012. Systematic review of outcomes of liver resection for early hepatocellular carcinoma within the Milan criteria. Br J Surg 99: 1622-1629.

Malinchoc M, Kamath PS, Gordon FD, Peine CJ, Rank J, ter Borg PC. 2000. A model to predict poor survival in patients undergoing transjugular intrahepatic portosystemic shunts. Hepatology 31: 864-871.
Meyers RL, Tiao GM, Dunn SP, Langham MR Jr. 2012. Liver transplantation in the management of unresectable hepatoblastoma in children. Front Biosci 4: 1293-1302.

National Institutes of Health. 1984. National Institutes of Health Consensus Development Conference Statement: Liver transplantation-June 20-23, 1983. Hepatology 4: 107S-110S.

Papafragkakis H, Martin P, Akalin E. 2010. Combined liver and kidney transplantation. Curr Opin Organ Transplant 15: $263-268$.

Pichlmayr R, Ringe B, Gubernatis G, Hauss J, Bunzendahl H. 1988. Transplantation of a donor liver to 2 recipients (splitting transplantation) - A new method in the further development of segmental liver transplantation. Langenbecks Archiv fur Chirurgie 373: 127-130.

Prokai A, Fekete A, Pasti K, Rusai K, Banki NF, Reusz G, Szabo AJ. 2012. The importance of different immunosuppressive regimens in the development of posttransplant diabetes mellitus. Pediatr Diabetes 13: 81-91.

Rice JP, Lucey MR. 2013. Should length of sobriety be a major determinant in liver transplant selection? Curr Opin Organ Transplant 18: 259-264.

Rosen CB, Heimbach JK, Gores GJ. 2010. Liver transplantation for cholangiocarcinoma. Transplant Int 23: 692697.

Said A, Williams J, Holden J, Remington P, Gangnon R, Musat A, Lucey MR. 2004. Model for end stage liver disease score predicts mortality across a broad spectrum of liver disease. J Hepatol 40: 897-903.

Scherer MN, Banas B, Mantouvalou K, Schnitzbauer A, Obed A, Kramer BK, Schlitt HJ. 2007. Current concepts and perspectives of immunosuppression in organ transplantation. Langenbecks Arch Surg 392: 511-523.

Schlitt HJ, Jonas S, Ganten TM, Grannas G, Moench C, Rauchfuss F, Obed A, Tisone G, Pinna AD, Gerunda GE, et al. 2013. Effects of mycophenolate mofetil introduction in liver transplant patients: Results from an observational, non-interventional, multicenter study (LOBSTER). Clin Transplant 27: 368-378.

Schnitzbauer AA, Scherer MN, Rochon J, Sothmann J, Farkas SA, Loss M, Geissler EK, Obed A, Schlitt HJ. 2010. Study protocol: A pilot study to determine the safety and efficacy of induction-therapy, de novo MPA and delayed mTOR-inhibition in liver transplant recipients with impaired renal function. PATRON-study. BMC Nephrol 11: 24 .

Shapiro HA. 1968. Brain death and organ transplantation. J Forensic Med 15: 89-90.

Shapiro R. 2004. Low toxicity immunosuppressive protocols in renal transplantation. Keio J Med 53: 18-22.

Song GW, Lee SG, Hwang S, Ahn CS, Moon DB, Kim KH, Ha TY, Jung DH, Park GC, Namgung JM, et al. 2013. Successful experiences of ABO-incompatible adult living donor liver transplantation in a single institute: No immunological failure in 10 consecutive cases. Transplant Proc 45: 272-275.

Starzl TE. 2012. The long reach of liver transplantation. Nat Med 18: 1489-1492.

Starzl TE, Marchioro TL, Vonkaulla KN, Hermann G, Brittain RS, Waddell WR. 1963. Homotransplantation of the liver in humans. Surg Gynecol Obstet 117: 659-676. 
Starzl TE, Groth CG, Brettschneider L, Penn I, Fulginiti VA, Moon JB, Blanchard H, Martin AJ Jr, Porter KA. 1968. Orthotopic homotransplantation of the human liver. Ann Surg 168: 392-415.

Starzl TE, Iwatsuki S, Klintmalm G, Schroter GP, Weil R III, Koep LJ, Porter KA. 1981a. Liver transplantation, 1980, with particular reference to cyclosporin-A. Transplant Proc 13: 281-285.

Starzl TE, Klintmalm GB, Porter KA, Iwatsuki S, Schroter GP. 1981b. Liver transplantation with use of cyclosporin a and prednisone. N Engl J Med 305: 266-269.

Tavio M, Grossi P, Baccarani U, Scudeller L, Pea F, Berretta M, Adani G, Vivarelli M, Riva A, Tirelli U, et al. 2011 HIV-infected patients and liver transplantation: Who, when and why. Current HIV Res 9: 120-127.

Thuluvath PJ, Yoo HY. 2004. Graft and patient survival after adult live donor liver transplantation compared to a matched cohort who received a deceased donor transplantation. Liver Transpl 10: 1263-1268.

Torbenson M, Wang J, Nichols L, Jain A, Fung J, Nalesnik MA. 1998. Causes of death in autopsied liver transplantation patients. Mod Pathol 11: 37-46.

United States Congress. 1984. National Organ Transplant Act: Public Law 98-507. US Statut Large 98: 2339-2348.

Watt KD, Pedersen RA, Kremers WK, Heimbach JK, Sanchez W, Gores GJ. 2009. Long-term probability of and mortality from de novo malignancy after liver transplantation. Gastroenterology 137: 2010-2017.

Yao FY. 2008. Liver transplantation for hepatocellular carcinoma: Beyond the Milan criteria. Am J Transplant 8: 1982-1989.

Zakhari S. 2013. Bermuda Triangle for the liver: Alcohol, obesity, and viral hepatitis. J Gastroenterol Hepatol 28: $18-25$. 


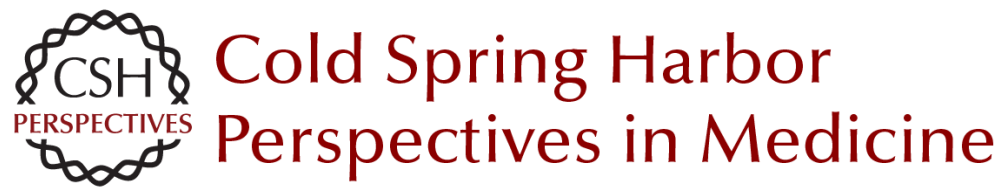

\section{Overview of the Indications and Contraindications for Liver Transplantation}

Stefan Farkas, Christina Hackl and Hans Jürgen Schlitt

Cold Spring Harb Perspect Med 2014; doi: 10.1101/cshperspect.a015602

Subject Collection Transplantation

Heart Transplantation: Challenges Facing the

Field

Makoto Tonsho, Sebastian Michel, Zain Ahmed, et al.

Bioethics of Organ Transplantation

Arthur Caplan

Overview of Clinical Lung Transplantation Jonathan C. Yeung and Shaf Keshavjee

Immunological Challenges and Therapies in

Xenotransplantation

Marta Vadori and Emanuele Cozzi

Clinical Aspects: Focusing on Key Unique

Organ-Specific Issues of Renal Transplantation Sindhu Chandran and Flavio Vincenti

T-Cell Costimulatory Blockade in Organ

Transplantation Jonathan S. Maltzman and Laurence A. Turka

Regulatory T-Cell Therapy in Transplantation:

Moving to the Clinic

Qizhi Tang and Jeffrey A. Bluestone

Opportunistic Infections--Coming to the Limits of Immunosuppression?

Jay A. Fishman
Overview of the Indications and Contraindications

for Liver Transplantation

Stefan Farkas, Christina Hackl and Hans Jürgen Schlitt

Facial and Hand Allotransplantation

Bohdan Pomahac, Ryan M. Gobble and Stefan Schneeberger

Induction of Tolerance through Mixed Chimerism David H. Sachs, Tatsuo Kawai and Megan Sykes

Pancreas Transplantation: Solid Organ and Islet Shruti Mittal, Paul Johnson and Peter Friend

Tolerance--Is It Worth It?

Erik B. Finger, Terry B. Strom and Arthur J. Matas

Lessons and Limits of Mouse Models

Anita S. Chong, Maria-Luisa Alegre, Michelle L. Miller, et al.

Effector Mechanisms of Rejection Aurélie Moreau, Emilie Varey, Ignacio Anegon, et al.

The Innate Immune System and Transplantation Conrad A. Farrar, Jerzy W. Kupiec-Weglinski and Steven H. Sacks

For additional articles in this collection, see http://perspectivesinmedicine.cshlp.org/cgi/collection/ 